\title{
4.7 Distance learning in the process of teaching English for law students: optimistic or skeptical challenges
}

Nowadays one of the most oft-used terms during the pandemic in the sphere of education, learning and teaching is distance learning. The COVID-19 pandemic has triggered such new ways of learning and teaching students in the universities and educational establishments. Law students are not the exception. That's why it is very actual to analyze problems, difficulties, advantages and disadvantages in order to have some positive or negative experience to share.

All around the world, educational institutions are looking toward online learning platforms to continue with the process of educating students. The new normal now is a transformed concept of education with online learning at the core of this transformation. Today, digital learning has emerged as a necessary resource for students and schools all over the world. For many educational institutions, this is an entirely new way of education that they have had to adopt. Online learning is now applicable not just to learn academics but it also extends to learning extracurricular activities for students as well. In recent months, the demand for online learning has risen significantly, and it will continue doing so in the future [271].

In the review of Doug Valentine University of Oklahome [272], we can trace the history of distance learning and the way the term has been defined in the past and how it is currently defined in the literature. The term can be used to describe any of a number of instructional situations. Although it is thought of as a new term, distance learning has been around for well over 100 years. One of the earlier forms of distance learning was done through correspondence courses started in Europe. This stayed the primary means of distance learning until the middle of this century when instructional radio and television became more popular (Imel, 1996). As technology has changed, so has the definition of distance learning. Videotaped lectures have been a standard in university and professional courses for the last two decades (Moore \& Lockee, 1998). Audiotapes and lessons sent through the mail have been used in correspondence courses to teach subjects such as foreign language for quite some time (Teaster \& Blieszner, 1999). 
Today, the Internet and compressed video have taken distance learning in new directions, allowing distance learning to occur in real time. Live video instruction is the most popular and fastest growing delivery mode in the United States (Ostendorf, 1997) [272].

Merriam Webster defines distance learning as, "a method of study where teachers and students do not meet in a classroom but use the Internet, e-mail, mail, etc., to have classes" [273].

There have been many definitions put forward in modern literature. Greenberg (1998) defines contemporary distance learning as "a planned teaching/learning experience that uses a wide spectrum of technologies to reach learners at a distance and is designed to encourage learner interaction and certification of learning" (pg. 36). Teaster and Blieszner (1999) say the term distance learning has been applied to many instructional methods: however, its primary distinction is that the teacher and the learner are separate in space and possibly time" (pg. 741). Desmond Keegan (1995) gives the most thorough definition. He says that distance education and training result from the technological separation of teacher and learner which frees the student from the necessity of traveling to "a fixed place, at a fixed time, to meet a fixed person, in order to be trained" (pg. 7). From these definitions we can see that the student and teacher are separated by space, but not necessarily by time. This would include compressed video, which is delivered in real time. As stated earlier, this type of live video instruction is the fastest growing means of distance learning today [272].

Referring to different definitions and explanations of the term distance learning, online learning, digital learning we fully agree with the thoughts that distance learning is basically a way of disseminating knowledge, where the educators and students are separated in distance or time or even both. Distance learning does not include any inperson interaction with an instructor or study peers. Students study at home on their own, and the learning is more individual and varies on speed and timeline according to each individual student and their availability. 
Distance learning actually relies on the educational tools of online learning, and that is probably why there is some confusion between the two. It is possible to study with online distance learning as well.

Online learning is when teachers or students use educational tools which are accessible on the internet as well. This means that students can also use online tools while they are physically in a classroom with their teachers. Online learning can be used anywhere and anytime, so teachers may have students using them as tools in class or for preparation and assignments at home. Online learning tools are often used to create blended learning environments in the classroom. This helps keep students engaged in the class and in the material.

Online learning also helps teachers save preparation time before class. With the help of online educational tools, teachers can spend more time grading papers, giving one-on-one attention to students, and maybe even getting some free time for themselves in their busy work schedule.

Undoubtedly, distance learning offers wide variety of opportunities to students to attain higher education, but it is not all about benefits and advantages indeed. The distance mode of education offers students the flexibility to decide, what they want to learn, when they want to learn, at what pace they want to learn and what they would like to learn. It is understood and well researched that not all students tend to learn via same technique of open learning and there is no particular technique that facilitate learning in everyone. There are several factors that affect student's capacity to study. Applied learning, interaction, prior knowledge, analytical skills and motivations are some of the factors [274].

As with most teaching English methods, online learning also has its own set of positives and negatives. Decoding and understanding these positives and negatives will help institutes in creating strategies for more efficient delivery of the classes, ensuring an uninterrupted learning journey for the students. 
Expressing opinions and probabilities, using our own experience of English Language in professional use teaching at Law Department of Lesya Ukrainka Volyn National University we define such advantages and of distance learning.

1. Efficiency. Online learning offers teachers an efficient way to deliver lessons to students. Online learning has a number of tools such as videos, PDFs, podcasts, and teachers can use all these tools as part of their lesson plans. By extending the lesson plan beyond traditional textbooks to include online resources, teachers are able to become more efficient educators.

2. Accessibility Of Time And Place. Another advantage of online education is that it allows students to attend classes from any location of their choice. It also allows schools to reach out to a more extensive network of students, instead of being restricted by geographical boundaries. Additionally, online lectures can be recorded, archived, and shared for future reference. This allows students to access the learning material at a time of their comfort.

3. Affordability. Another advantage of online learning is reduced financial costs. Online education is far more affordable as compared to physical learning. This is because online learning eliminates the cost points of student transportation, student meals, and most importantly, real estate. Additionally, all the course or study materials are available online, thus creating a paperless learning environment which is more affordable, while also being beneficial to the environment.

4. Improved Student Attendance. Since online classes can be taken from home or location of choice, there are fewer chances of students missing out on lessons.

In other words we can study anywhere, anytime, any place. Distance learning is student centered. Access to Resources is great one. Today students have access to resources and materials that may be physically located anywhere in the world. An instructor can compile a resource section online with links to scholarly articles, institutions, and other materials relevant to the course topic for students to access for research, extension, or in depth analysis of course content material. Teaching is becoming more and more creative, we, teachers seek new forms and methods of teaching and presenting material. 
Besides, we have resulted from our own online learning experience some disadvantages. The first one, and is the most useful in our point of view that we teachers, and our students have no physical interaction. When the physical interaction between teachers and students is missing, then students tend to lose personal interaction with their educators and thereby the mental buildup of students may get hampered. Most of the students prefer to learn when their educators are physically present in the classroom. So, for such students distance learning would not be beneficial indeed.

It goes without saying, distance learning is less motivational. In distance learning, students are not required to attain classroom in person. They are isolated and hence they don't get same sort of interaction with other fellow colleagues in the course. Besides, the educators will also not be able to interact with the student directly; therefore they can't motivate the students as they do in classroom. In traditional way of learning, the students get the opportunity to thrive in an environment. In distance mode of learning, all these motivational factors are not present and can be unfavorable for many students.

Distance learning doesn't help in developing oral skills and social interaction, most of the distance learning courses don't facilitate oral communication, unless the program is synchronous learning event, where the students are asked to participate by using some communication techniques. This idea concerns such courses as English in Professional Use (Law), Academic Writing, Legal Writing.

Another difficulty we face in the process of teaching English that distance is the requirement of sound technical skills; this includes good typing skills to excel in distance learning setup. Distance learning also includes some hidden cost, like maintenance and purchasing of computer and other equipments to succeed in the learning process. Another key challenge of online classes is internet connectivity. While internet penetration has grown in leaps and bounds over the past few years, in smaller cities and towns, remoted villages a consistent connection with decent speed is a problem. Without a consistent internet connection for students or teachers, there can be a lack of continuity in learning for the student. 
For many students and teachers as well, one of the biggest challenges of online learning is the struggle with focusing on the screen for long periods of time. With online learning, there is also a greater chance for students to be easily distracted by social media or other sites. Therefore, it is imperative for the teachers to keep their online classes crisp, engaging, and interactive to help students stay focused on the lesson.

Students can learn a lot from being in the company of their group mates. However, in an online class, there are minimal physical interactions between students and teachers. This often results in a sense of isolation for the students. In this situation, it is imperative that the school allow for other forms of communication between the students, peers, and teachers. This can include online messages, emails and video conferencing that will allow for face-to-face interaction and reduce the sense of isolation.

In order to successfully participate in an online classes, students must be well organized, self-motivated, and possess a high degree of time management skills in order to keep up with the pace of the course.

We fully agree with above mentioned author of great research on distance learning of Doug Valentine University of Oklahome [272], towards instructor concerns. It is underlined that Instructors worry about putting their course materials online because once there, the knowledge and course design skill in that material is out of their possession. This puts the administration in a position to hire less skilled, and cheaper, workers to deliver the technologically prepackaged course (Noble, 1998 cited in Dibiase, 2000). Instructors are not always convinced that administration is behind distance learning. The rewards are not always there for the good distance-learning instructor. The increased amount of time necessary to adequately prepare for distance learning takes away from the activities they will be evaluated on, such as grant writing and publishing. Many of the instructors concerns are valid and should be addressed by administration as distance learning becomes more common, as is predicted to happen [272]. 
If to speak about distance learning process at our university, Faculty of Law, we try to combine all kinds of online courses. For instance, Conference classes, which allow students and teachers to meet up for class in real time, whether in a group or oneon-one with an instructor. Using the phone or video chatting, such as Skype, Viber students and teachers can engage in live lessons despite distance.

Correspondence courses which consist of students engaging in class material via mail or email. Students receive material and assignments through mail, and they send completed assignments back through the same method. These courses are reflected in Google Classroom Platform or our university platform Office 365.

Hybrid courses which combine traditional classroom settings with online learning at home. This can mean that students learn individually at home and meet up for inperson instructions or lectures at certain intervals during the course. The amount of athome learning and in-class learning varies for each hybrid course.

Being involved in a collaborative learning process is an important part of forming the foundation of a learning community. When this is not encouraged, participation is generally low and dialog is absent (Palloff \& Pratt, 2000). Students also need the attention of the instructors. This may be truer in a distance situation than in a traditional classroom. In a situation where eye contact and proximity are limited, students cannot be disciplined nor affirmed by eye contact and body language (McKnight, 2000). Students may also have a difficult time reading the reactions of the remote location class members many experts now contend that [272].

As for me, I prefer to work with students in the classroom, to feel them, to feel their mood, to communicate, to have real feedback. But it was and is not very easy to combine all these types of work with future lawyers because of the peculiarities of law specialty.

All educators approach this new paradigm with varying degrees of enthusiasm and concern. Are you optimistic or skeptical about Online Learning? Are you interested in knowing how delivering courses online can improve your teaching and offer unprecedented learning opportunities for your students, or do you want to know what you will be up against as you plan and deliver your classes online? It is important to 
consider both the pros and cons of online learning so you can be better prepared to face the challenge of working in this new environment as well as embrace the new opportunities that it has to offer.

Now when we have a rundown of the distance learning definition, and the different kinds that are available, you can decide whether it's a right fit for you and your life. Many students find distance learning to be a fulfilling and practical way to receive quality education, without needing to attend a traditional university.

But nonetheless, virtual learning still serves as major convenience and efficiency in delivering content with no physical constraints, especially nowadays, in a time of global crisis. We teachers, are really facing that challenge and we are to carry out an important task for the university, community, country, which deserves to be praised and which can bring about innovation in schools like never before. 